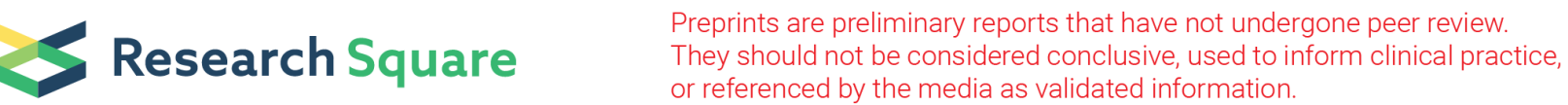

\section{Overexpression of programmed cell death-1 on circulatory Th1 and Th2 cells in cardiac arrest patients in the early period after the return of spontaneous circulation}

\section{Yanan Yu}

Capital Medical University Affiliated Beijing Friendship Hospital

Chunsheng Li ( $D$ lcscyyy@163.com)

Capital Medical University Afflliated Beijing Friendship Hospital https://orcid.org/0000-0002-31614457

Miaorong Xie

Capital Medical University Affiliated Beijing Friendship Hospital

\section{Ziren Tang}

Beijing Chaoyang Hospital

Jiabao Li

Capital Medical University Affiliated Beijing Friendship Hospital

Chenchen Hang

Beijing Chaoyang Hospital

\section{Fei Shao}

Beijing Chaoyang Hospital

\section{Original research}

Keywords: Cardiac arrest, Programmed cell death-1, Immunosuppression, T helper type 1 cell, $T$ helper type 2 cell, Cytokines

Posted Date: April 29th, 2020

DOI: https://doi.org/10.21203/rs.3.rs-25305/v1

License: (c) (1) This work is licensed under a Creative Commons Attribution 4.0 International License. Read Full License 


\section{Abstract}

Background: In patients with immune disorders, the role of T-helper (Th) cells immediately following the return of spontaneous circulation (ROSC) after cardiac arrest is unclear. We evaluated the influence of plasma cytokine and programmed cell death-1 (PD-1) expression on circulating Th1 and Th2 cells and elucidated their role in immune function immediately following ROSC.

Methods: We enrolled 92 non-consecutive cardiac arrest patients that experienced ROSC between 6 and $24 \mathrm{~h}$ post-cardiac arrest as well as 40 healthy controls. Outcome data were collected 28 days after ROSC. Peripheral blood samples were analyzed to determine Th1 and Th2 cell counts and PD-1 expression. The plasma levels of cytokines, including interferon- $\gamma$, tumor necrosis factor-a, interleukin (IL)-4, IL-6, and IL-10 were determined.

Results: Compared with those in healthy individuals, Th1 and Th2 cell counts and Th1/Th2 cell ratios in CA patients after ROSC were significantly reduced $(P<0.05)$. The percentages of $P D-1$ expression were significantly higher in Th1 and Th2 cells $(P<0.01)$. There were no significant differences in Th1 and Th2 cell expression of PD- 1 between survivors and non-survivors. Plasma levels of IL- 6 and IL-10 in ROSC patients were significantly higher during the early period $(P<0.05)$.

Conclusions: Th1 and Th2 cell expression of PD-1 is upregulated in the period immediately following ROSC in cardiac arrest patients and may be responsible for the observed immunosuppression in these patients during this period.

\section{Background}

Cardiac arrest (CA) is the leading cause of morbidity and mortality of hospitalized patients globally and has low rates of overall survival (1). It is estimated that more than 544,000 deaths due to cardiac arrest occur annually in China (2). After the return of spontaneous circulation (ROSC), CA patients with systemic ischemia/reperfusion injury (IRI) can manifest 'sepsis-like' syndromes and immune disorders which can lead to infections (3-5).

CD4 + T lymphocytes are effector cells in the adaptive immune system of humans and play important roles in fighting infections and the pathogenesis of IRI $(6,7)$. Upon activation of the T cell receptor (TCR), naïve $C D 4^{+} \mathrm{T}$ lymphocytes differentiate into T-helper 1 (Th1), and Th2 subsets (8-10). The balance among Th1, Th2, and regulatory $\mathrm{T}$ (Treg) cells regulates immune functions and inflammatory responses. Th2 and Treg cells dominate the early peripheral blood of patients with sepsis and ROSC and can prevent the ability of patients to fight infection effectively (11-13).

Programmed cell death-1 (PD-1) is an inhibitory receptor involved in the regulation of T lymphocyte-based immune responses (14). PD-1 inhibits the production of interferon (IFN)-y, as well as Th1-mediated cellular responses, and enhances the production of IL-4 and Th2 cell-mediated responses $(15,16)$. PD-1 expression in the early circulating Treg cells increases in CA patients after ROSC (17). However, whether 
the expression of PD-1 on Th1 and Th2 cells correlates with immune dysfunction after ROSC is still unknown. In this study, we aimed to evaluate an early immune function in CA patients after ROSC by investigating the changes in PD-1 expression on Th1 and Th2 cells and plasma cytokine levels, including IL-6, IL-10, IFN- - , tumor necrosis factor (TNF)-a, and IL-4.

\section{Methods}

\section{Study participants}

This study was approved by the Medical Ethics Committee at the Beijing Friendship Hospital. Since this was an observational study based on the residual blood samples taken every morning after the measurement of the levels of routine biomarkers, we did not need informed consent from patients according to the 2015 International Cardiopulmonary Resuscitation Guidelines (18). We performed enrolment assessments for CA patients after their admission to the emergency departments of these hospitals between October 2018 and September 2019 after ROSC. The inclusion criteria were ROSC $>6 \mathrm{~h}$ and $<24 \mathrm{~h}$, and Glasgow coma score $<8$ after ROSC. The exclusion criteria included patients $<18$ years old, patients with significantly infected organs or tissues, patients at the end stage of any malignancy or acquired immunodeficiency syndrome, and patients that received immunosuppressants within the last 3 months. All patients were treated according to the 2015 International Cardiopulmonary Resuscitation Consensus (19). The control group was recruited after a physical examination and was comprised of ageand gender-matched healthy individuals.

\section{Data collection}

We collected demographic information for the enrolled patients including data related to resuscitation (initial heart rhythm, ROSC time, and cumulative adrenaline (epinephrine) dose); and laboratory data (routine blood cell, blood gas, and blood biochemical tests performed more than $6 \mathrm{~h}$ after ROSC). Acute Physiology and Chronic Health Evaluation (APACHE) II and Sequential Organ Failure Assessment (SOFA) scores were used to determine the severity of the disease. Residual blood samples from routine clinical tests or physical health examinations were collected and maintained at $4{ }^{\circ} \mathrm{C}$ during transport and storage before they were used to determine the level of PD-1 expression by Th1 and Th2 cells and the levels of plasma cytokines and how changes in PD-1 expression impact Th1 and Th2 cells. During follow-up, 28day survival data were collected. The workflow of this study is shown in Supplemental Fig. 1.

\section{Flow cytometry}

Within $2 \mathrm{~h}$ of collecting the blood samples, $1 \mathrm{ml}$ of peripheral blood sample was mixed with BD Leukocyte Activation Cocktail with BD GolgiPlug (BD Bioscience, San Diego, USA) in a 24-well cell culture plate (Corning, Manassas, USA) as per the manufacturer's instructions followed by incubation at $37^{\circ} \mathrm{C}$, under humidified conditions and $5 \% \mathrm{CO} 2$ for $4 \mathrm{~h}$.

After incubation, surface staining was performed using antibodies against cluster-of-differentiation (CD)3 (Catalog NO. 558117), CD8 (Catalog NO. 557746), and PD-1 (Catalog NO. 558694) at $4{ }^{\circ} \mathrm{C}$ for 20 min. 
Subsequently, the cells were lysed, washed, and fixed using Fix/Perm Buffer (Transcription Factor Buffer Set, Catalog NO. 562574) at $4{ }^{\circ} \mathrm{C}$ for $40 \mathrm{~min}$. The cells were then washed with the Perm/Wash Buffer (Transcription Factor Buffer Set, Catalog NO. 562574). Intracellular staining for cytokines was performed using the following antibodies: IFN-Y (Catalog NO. 554701) and IL-4 (Catalog NO. 554516). The cells were incubated at $4{ }^{\circ} \mathrm{C}$ for 40 min before they were analyzed using the Gallios ${ }^{\mathrm{TM}}$ flow cytometer (Beckman Coulter, Inc., Brea, CA, USA). All the above antibodies were purchased from Becton Dickinson Company and were used as per the recommendations: Pacific Blue Mouse Anti-Human CD3, PE-Cy7 Mouse AntiHuman CD8, APC Mouse Anti-Human CD279, PE Mouse Anti-Human IFN-y, and PE Mouse Anti-Human IL4.

The data were analyzed using the Gallios software (version 1.0). Lymphocytes were first gated by forward and side scatter. $\mathrm{CD} 4^{+} \mathrm{T}$ cells were represented by the $\mathrm{CD} 3^{+} \mathrm{CD} 8^{-}$population. Th1 and Th2 cells were represented by the $\mathrm{CD}^{+}{ }^{+} \mathrm{CD} 8^{-} \mathrm{IFN}-\mathrm{y}^{+}$and $\mathrm{CD} 3^{+} \mathrm{CD} 8^{-} \mathrm{IL}-4^{+}$populations, respectively. Thresholds were defined using the isotype controls. Results were expressed as percentages. The flow cytometry gating strategy is shown in Fig. 1.

\section{T lymphocyte content}

Flow-Count fluorescent spheres (Beckman Coulter, Inc.) were used to determine the absolute counts of CD3 + lymphocytes as per the manufacturer's instructions. The relative contents of Th1 and Th2 cells were calculated from $\mathrm{CD} 3^{+} \mathrm{CD} 8^{-}$to $\mathrm{CD} 3^{+}$lymphocyte ratios.

\section{Plasma cytokines levels}

Plasma cytokines IFN- - , TNF-a, IL-4, IL-6, and IL-10 were passed through a Luminex array (ProcartaPlex, Ebioscience) using the Bio-Rad Luminex 200 instrument (Bio-Rad, Hercules). The detection limit was $\geq$ $0 \mathrm{pg} / \mathrm{mL}$. Most patients showed IL-4 levels below the detection limit. Detectable levels of IFN- $\gamma$ and TNF-a were only found in $31 \%$ and $37.9 \%$ of the patients, respectively, and therefore were not reported.

\section{Statistical Analysis}

All data were analyzed using SPSS Version 22.0 (SPSS Inc., Chicago, IL, USA) and GraphPad Prism, Version 8.0 (GraphPad Software, USA). For normally distributed data, continuous variables were expressed as mean \pm standard deviation (SD). As the data for IL- 6 and IL-10 had skewed distribution, we compared the values of In (IL-6 + 1) and In (IL-10 + 1) obtained by natural logarithmic conversion after adding 1 to the results. Measurement data with a skewed distribution have been expressed as medians (25th and 75th percentiles). Mann-Whitney $U$ test was carried out for statistical comparison between groups. The qualitative parameters in the $2 \times 2$ contingency table were used for analysis. All statistical tests were two-tailed and $\mathrm{P}<0.05$ was considered statistically significant.

\section{Results}


The study included 92 CA patients and 40 healthy individuals. The demographic and clinical characteristics of patients with CA are presented in Table 1. In this study, acute cardiac and brain events were the main causes of CA. Other causes included poisoning (including fuel and carbon monoxide poisoning) and hypokalemia. Patient gender and age were not significantly different between CA and healthy control groups. Based on the 28-day survival data, CA patients were divided into survivors and non-survivors. Patient characteristics are shown in Table 2. Compared to the survivors, non-survivors received higher doses of adrenaline ( 1.0 vs. $3.0 \mathrm{mg}, \mathrm{P}=0.03)$. The APACHE II and SOFA scores were significantly different between $C A$ and healthy control groups $(P<0.001$ for all). There were significant differences in the APACHE II scores, but not the SOFA scores, between survivors and non-survivors $(P=0.002$, and $P=0.07)$.

\section{Th1 and Th2 cell counts and Th1/Th2 cell ratios}

Compared with the healthy controls, CA patients had significant reductions in Th1 $(P<0.001)$ and Th2 $(P=0.03)$ cell counts and in the Th1/Th2 cell ratios $(P<0.001)$ in the period immediately following ROSC. Th1/CD $4^{+}$lymphocyte ratios were not significantly different $(P=0.74)$, but Th2/CD4 $4^{+}$lymphocyte ratios increased significantly $(P<0.001)$ (Supplemental Table 1). Survivors $(n=21)$ and non-survivors $(n=71)$ were classified based on their 28-day survival rates. There were no significant differences in Th1 and Th2 cell counts, CD4 ${ }^{+}$lymphocytes ratios, and Th1/Th2 lymphocyte ratios between survivors and nonsurvivors $(P>0.05$ for all) (Supplemental Table 2).

PD-1 expressed by Th1 and Th2 cells

Compared with those in healthy individuals, there was a significant increase in the percentages of PD- $1^{+}$ Th1 $(P=0.007)$ and Th2 $(P=0.008)$ cells in CA patients after ROSC (Figure 2A, B). No statistical differences in the PD-1 expression by Th1 and Th2 cells were observed between survivors and nonsurvivors ( $P>0.05$ for all) (Figure 2C, D).

\section{Changes in plasma cytokines}

We measured plasma IL- 6 and IL-10 levels of 40 healthy individuals and 87 CA patients (IL- 6 and IL-10 levels were not available for 5 CA patients). We compared the values of $\ln (\mathrm{IL}-6+1)$ and $\ln (\mathrm{IL}-10+1)$ obtained by natural logarithmic conversion after adding 1 to the results because the data for IL- 6 and IL10 had skewed distributions. The $\ln (\mathrm{IL}-6+1)$ and $\ln (\mathrm{IL}-10+1)$ values were higher in CA patients after ROSC than in healthy individuals ( $P=0.02$ and 0.03 , respectively) (Figure 3A, B). No statistical differences in $\ln (\mathrm{IL}-6+1)$ and $\ln (\mathrm{IL}-10+1)$ values between survivors and non-survivors were observed $(P=0.17$ and 0.07 , 
respectively) (Figure 3C, D). However, non-survivors had higher $\ln (\mathrm{IL}-6+1)$ and $\ln (\mathrm{IL}-10+1)$ values than survivors.

\section{Discussion}

We observed increased PD-1 expression in circulating Th1 and Th2 cells, which may be related to the increased susceptibility to infection experienced by CA patients in the period immediately following ROSC. In CA patients, increased plasma IL- 6 and IL-10 levels were observed. The expression level of PD-1 by Th2 cells was found to be positively correlated with the level of IL-6. No statistical differences were found in cytokine levels between survivors and non-survivors.

In CA patients following ROSC, Th1 and Th2 cell counts and Th1/Th2 cell ratios decreased, which was consistent with results from previous studies (13). After ROSC, the count of Treg cells decreased in CA patients, but the proportion increased. (17). In vitro, PD-1 inhibits Th1 responses by inducing Treg cells and stimulating Th2 responses $(15,16,20-22)$. Therefore, increased expression of PD-1 may shift the Th1/Th2 balance towards Th2 in CA patients in the critical period following ROSC.

The percentage of PD $-1^{+}$Th1 and PD $-1^{+}$Th2 cells was increased in CA patients in the period immediately following ROSC. Previous studies have found a relative increase in the percentage of PD-1 ${ }^{+}$Treg cells in CA patients following ROSC and elevated PD-1 expression by $\mathrm{T}$ lymphocytes in patients with severe sepsis $(17,23)$. This indicates that high expression of PD-1 by Th1 and Th2 cells may be involved in T cell-mediated immunosuppression. In non-survivors, a reduction in PD-1 expression by Th cells was found; however, this was not significant. PD-1 expression by Treg cells was decreased in non-survivors, which may indicate severe suppression of immune function (17). We speculate that decreased PD-1 expression by circulating Th cells may suppress the immune function of CA patients, increasing their susceptibility to infection.

In CA patients in the period immediately following ROSC, levels of plasma pro-inflammatory cytokine IL-6 and anti-inflammatory cytokine IL-10 were significantly increased, which is consistent with the results of previous studies $(24,25)$. While IL- 6 can induce Th2 cell differentiation, IL-10 can regulate excessive Th1 cell responses $(8,26)$, indicating that high IL- 6 and IL-10 levels in plasma during the early period after ROSC may be associated with Th1/Th2 imbalance. Recent studies have shown that IL- 6 and PD-1 jointly participate in immune suppression in the tumor microenvironment (27). Patients with high PD-1

expression have increased IL-10 levels when experiencing septic shock (28). The release of IL-6 and IL-10 is related to the severity of post-cardiac arrest syndrome (PCAS) and high levels of IL-6 are independently associated with increased mortality in CA patients $(24,25,29)$. These suggest that immune suppression, susceptibility, and prognosis in the early period after ROSC may be determined by the levels of plasma IL6 and IL-10 as well as PD-1 expression by Th cells.

This study has several limitations. First, blood collection was performed at a single time point. Although many changes were observed in the preliminary observational studies, we could not focus on the 
subsequent dynamic observations. In addition, some cytokines are released into the blood and reach their peaks at different times. If the samples were not collected at the appropriate time, they would not have been effectively evaluated. Second, the heterogeneity in CA patients after ROSC made subgroup analysis difficult. The patients were not stratified by age, gender, or the occurrence of comorbidities. Thus, the effects of these factors on the results cannot be ruled out. Third, baseline samples were not collected for analysis immediately after admission. Future experimentation will track the expression of PD-1 by Th1 and Th2 cells of patients over time and evaluate how changes in PD-1 expression correlates with changes in immune function. This will allow the exploration of the relationship between PD-1 expression and easy-to-measure clinical commonly used biomarkers in CA patients after ROSC to promote the clinical application of therapeutic PD-1 blockers in the future.

\section{Conclusions}

Increased PD-1 expression, imbalanced Th1/Th2 ratios, and increased plasma levels of cytokines IL-6 and IL-10 were manifested in CA patients in the period immediately following ROSC. In CA patients following ROSC, upregulation of PD-1 by Th1 and Th2 cells may be related to immunosuppression.

\section{Abbreviations}

CA: Cardiac arrest, ROSC: Return of spontaneous circulation, IRI: Ischemia-reperfusion injury, PCAS: Post cardiac arrest syndrome, SIRS: Systematic inflammatory response syndrome, PD-1: Programmed cell death 1, Th: T helper, CD: Cluster-of-differentiation, IL: Interleukin.

\section{Declarations}

\section{Ethics approval and consent to participate}

Ethics approval and waiver of consent to participate was approved by the Beijing Friendship Hospital. The data collected does not contain identifying information.

\section{Consent for publication}

Not applicable.

\section{Availability of data and materials}

The datasets used in the present study are available from the first and corresponding authors by reasonable request.

\section{Competing interests}

The authors declare that they have no competing interests. 


\section{Funding}

Not applicable.

\section{Authors' contributions}

C Li designed the study, YNY, CCH, and JBL collected and analyzed data, and contributed to writing this manuscript. FS and MRX helped with data analysis. All authors have read and approved the final manuscript.

\section{Acknowledgments}

We would like to thank all the researchers who participated in this study and our colleagues who assisted us.

\section{Authors' information}

The first author, YNY, is a student of the corresponding author, Professor Chunsheng Li. This study was performed at Beijing Chaoyang Hospital; however, our personnel affiliations have transferred to Beijing Friendship Hospital.

\section{References}

1. Myat A, Song KJ, Rea T. Out-of-hospital cardiac arrest: current concepts. Lancet. 2018;391:970-9.

2. Zhang S. Sudden cardiac death in China: current status and future perspectives. Europace. 2015;17(Suppl 2):ii14-8.

3. Tsai MS, Chiang WC, Lee CC, Hsieh CC, Ko PC, Hsu CY, et al. Infections in the survivors of out-ofhospital cardiac arrest in the first 7 days. Intensive Care Med. 2005;31:621-6.

4. Nolan JP, Neumar RW, Adrie C, Aibiki M, Berg RA, Bottiger BW, et al. Post-cardiac arrest syndrome: epidemiology, pathophysiology, treatment, and prognostication. A Scientific Statement from the International Liaison Committee on Resuscitation; the American Heart Association Emergency Cardiovascular Care Committee; the Council on Cardiovascular Surgery and Anesthesia; the Council on Cardiopulmonary, Perioperative, and Critical Care; the Council on Clinical Cardiology; the Council on Stroke. Resuscitation. 2008;79:350-79.

5. Su CP, Wu JH, Yang MC, Liao CH, Hsu HY, Chang CF, et al. Demographics and clinical features of postresuscitation comorbidities in long-term survivors of out-of-hospital cardiac arrest: A national follow-up study. Biomed Res Int. 2017;2017:9259182.

6. Rao J, Lu L, Zhai Y. T cells in organ ischemia reperfusion injury. Curr Opin Organ Transplant. 2014;19:115-20.

7. Wu H, Wang K, Li G, Meng D, Han J, Wang G, et al. Effects of transcutaneous acupoint electrical stimulation on the imbalance of Th1, Th2, Th17 and Treg cells following thoracotomy of patients 
with lung cancer. Exp Ther Med. 2016;11:495-502.

8. Zhu J, Yamane H, Paul WE. Differentiation of effector CD4 T cell populations $\left(^{*}\right)$. Annu Rev Immunol. 2010;28:445-89.

9. Yoon SJ, Kim SJ, Lee SM. Overexpression of HO-1 contributes to sepsis-induced immunosuppression by modulating the Th1/Th2 balance and regulatory T-Cell function. J Infect Dis. 2017;215:1608-18.

10. Raphael I, Nalawade S, Eagar TN, Forsthuber TG. T cell subsets and their signature cytokines in autoimmune and inflammatory diseases. Cytokine. 2015;74:5-17.

11. Wu HP, Chung K, Lin CY, Jiang BY, Chuang DY, Liu YC. Associations of T helper 1, 2, 17 and regulatory T lymphocytes with mortality in severe sepsis. Inflamm Res. 2013;62:751-63.

12. Gupta DL, Bhoi S, Mohan T, Galwnkar S, Rao DN. Coexistence of Th1/Th2 and Th17/Treg imbalances in patients with post traumatic sepsis. Cytokine. 2016;88:214-21.

13. Qi ZJ, Zhang Q, Liu B, Shao H, Li CS. Early changes in circulatory T helper type 1, 2, and 17 cells of patients with out-of-hospital cardiac arrest after successful cardiopulmonary resuscitation. Chin Med J (Engl). 2018;131:2071-9.

14. Xia Q, Wei L, Zhang Y, Sheng J, Wu W, Zhang Y. Immune checkpoint receptors Tim-3 and PD-1 regulate monocyte and t lymphocyte function in septic patients. Mediators Inflamm. 2018;2018:1632902.

15. Dulos J, Carven GJ, van Boxtel SJ, Evers S, Driessen-Engels LJ, Hobo W, et al. PD-1 blockade augments Th1 and Th17 and suppresses Th2 responses in peripheral blood from patients with prostate and advanced melanoma cancer. J Immunother. 2012;35:169-78.

16. McAlees JW, Lajoie S, Dienger K, Sproles AA, Richgels PK, Yang Y, et al. Differential control of CD4(+) T-cell subsets by the PD-1/PD-L1 axis in a mouse model of allergic asthma. Eur $\mathrm{J}$ Immunol. 2015;45:1019-29.

17. Qi Z, Liu Q, Zhang Q, Liu B, Li C. Overexpression of programmed cell death-1 and human leucocyte antigen-DR on circulatory regulatory $T$ cells in out-of-hospital cardiac arrest patients in the early period after return of spontaneous circulation. Resuscitation. 2018;130:13-20.

18. Perkins GD, Travers AH, Berg RA, Castren M, Considine J, Escalante R, et al. Part 3: Adult basic life support and automated external defibrillation: 2015 International Consensus on Cardiopulmonary Resuscitation and Emergency Cardiovascular Care Science with Treatment Recommendations. Resuscitation. 2015;95:e43-69.

19. Soar J, Callaway CW, Aibiki M, Bottiger BW, Brooks SC, Deakin CD, et al. Part 4: Advanced life support: 2015 International Consensus on Cardiopulmonary Resuscitation and Emergency Cardiovascular Care Science with Treatment Recommendations. Resuscitation. 2015;95:e71-120.

20. Francisco LM, Sage PT, Sharpe AH. The PD-1 pathway in tolerance and autoimmunity. Immunol Rev. 2010;236:219-42.

21. Zhang Y, Liu Z, Tian M, Hu X, Wang L, Ji J, et al. The altered PD-1/PD-L1 pathway delivers the 'onetwo punch' effects to promote the Treg/Th17 imbalance in pre-eclampsia. Cell Mol Immunol. 2018;15:710-23. 
22. Kanno Y, Vahedi G, Hirahara K, Singleton K, O'Shea JJ. Transcriptional and epigenetic control of T helper cell specification: molecular mechanisms underlying commitment and plasticity. Annu Rev Immunol. 2012;30:707-31.

23. Jia Y, Zhao Y, Li C, Shao R. The expression of programmed death-1 on CD4 + and CD8 + T lymphocytes in patients with type 2 diabetes and severe sepsis. PLoS One. 2016;11:e0159383.

24. Bro-Jeppesen J, Kjaergaard J, Wanscher M, Nielsen N, Friberg H, Bjerre M, et al. The inflammatory response after out-of-hospital cardiac arrest is not modified by targeted temperature management at 33 degrees $C$ or 36 degrees C. Resuscitation. 2014;85:1480-7.

25. Peberdy MA, Andersen LW, Abbate A, Thacker LR, Gaieski D, Abella BS, et al. Inflammatory markers following resuscitation from out-of-hospital cardiac arrest-A prospective multicenter observational study. Resuscitation. 2016;103:117-24.

26. Li MO, Flavell RA. Contextual regulation of inflammation: a duet by transforming growth factor-beta and interleukin-10. Immunity. 2008;28:468-76.

27. Tsukamoto H, Fujieda K, Miyashita A, Fukushima S, Ikeda T, Kubo Y, et al. Combined Blockade of IL6 and PD-1/PD-L1 Signaling Abrogates Mutual Regulation of Their Immunosuppressive Effects in the Tumor Microenvironment. Cancer Res. 2018;78:5011-22.

28. Guignant C, Lepape A, Huang X, Kherouf H, Denis L, Poitevin F, et al. Programmed death-1 levels correlate with increased mortality, nosocomial infection and immune dysfunctions in septic shock patients. Crit Care. 2011;15.

29. Bro-Jeppesen J, Kjaergaard J, Wanscher M, Nielsen N, Friberg H, Bjerre M, et al. Systemic inflammatory response and potential prognostic implications after out-of-hospital cardiac arrest: a substudy of the target temperature management trial. Crit Care Med. 2015;43:1223-32.

\section{Tables}

Table 1. Patient characteristics on admission. 


\begin{tabular}{|c|c|c|c|}
\hline Characteristics & $\begin{array}{l}\text { Healthy Control Group } \\
(n=40)\end{array}$ & $\begin{array}{l}\text { CA Group } \\
(n=92)\end{array}$ & $\begin{array}{l}\text { P- } \\
\text { Value }\end{array}$ \\
\hline Age (years), median [IQR] & $64.0(54.0-70.0)$ & $65.0(55.0-74.0)$ & 0.23 \\
\hline Male/Female (n) & $23 / 17$ & $64 / 28$ & 0.18 \\
\hline \multicolumn{4}{|l|}{ Previous medical history, n (\%) } \\
\hline Hypertension & $5(12.5)$ & $38(41.8)$ & 0.001 \\
\hline Diabetes & $4(10.0)$ & $27(29.7)$ & 0.02 \\
\hline Coronary heart disease & $2(5.0)$ & $31(34.1)$ & $<0.001$ \\
\hline Chronic lung disease & $1(2.5)$ & $9(9.9)$ & 0.27 \\
\hline Chronic kidney disease & 0 & $9(9.9)$ & 0.09 \\
\hline \multicolumn{4}{|l|}{ Cardiac arrest cause (n, \%) } \\
\hline Cardiac & & $38(41.8)$ & \\
\hline Respiratory & & $21(23.1)$ & \\
\hline Cerebral & & $23(25.3)$ & \\
\hline Others & & $9(9.9)$ & \\
\hline Unknow & & $1(1.1)$ & \\
\hline \multicolumn{4}{|l|}{ Initial resuscitation } \\
\hline Time to ROSC (min), median [IQR] & & $20.0(10.0-30.0)$ & \\
\hline Adrenaline (mg), median [IQR] & & $2.0(0.0-5.0)$ & \\
\hline Initial rhythm VF/VT, n (\%) & & $34(37.4)$ & \\
\hline MAP (mmHg), median [IQR] & $96.0(86.0-103.0)$ & $74.0(56.0-100.0)$ & $<0.001$ \\
\hline $\begin{array}{l}\text { White cell count }(\times 109 / \mathrm{L}) \text {, median } \\
{[\mathrm{IQR}]}\end{array}$ & $5.81(4.85-6.53)$ & $\begin{array}{l}13.46(10.76- \\
18.37)\end{array}$ & $<0.001$ \\
\hline APACHE $\mathrm{score}$, mean \pm SD & 0 & $33.1 \pm 6.6$ & $<0.001$ \\
\hline SOFA score, median [IQR] & 0 & $11.5(8.3-14.8)$ & $<0.001$ \\
\hline 28-day mortality, n (\%) & & $71(78.0 \square$ & \\
\hline 28-day CPC 1-2, n (\%) & & $14(15.4)$ & \\
\hline
\end{tabular}

Data are presented as mean \pm SD or Interquartile Range (IQR) as appropriate. The p-value represents comparison between groups. Abbreviations: ROSC: return of spontaneous circulation; VF: ventricular fibrillation; VT: ventricular tachycardia; MAP: mean arterial pressure; APACHE $\square$ : acute physiology and chronic health evaluation; SOFA: sequential organ failure assessment; CPC: cerebral performance category. 
Table 2. Clinical characteristics of survivors and non-survivors over a period of 28-day post-ROSC

\begin{tabular}{|c|c|c|c|}
\hline & Survivors $(\mathrm{n}=21)$ & $\begin{array}{l}\text { Non-survivors } \\
(\mathrm{n}=71)\end{array}$ & $\begin{array}{l}\text { P- } \\
\text { Value }\end{array}$ \\
\hline Age (years), median [IQR] & $61.0(53.0-73.0)$ & $66.0(58.0-75.0)$ & 0.14 \\
\hline Male/Female (n) & $13 / 8$ & $51 / 20$ & 0.39 \\
\hline \multicolumn{4}{|l|}{ Cardiac arrest cause (n, \%) } \\
\hline Cardiac & $10(47.6)$ & $28(38.4)$ & 0.45 \\
\hline Non-Cardiac & $11(52.4)$ & $43(60.6)$ & 0.50 \\
\hline \multicolumn{4}{|l|}{ Initial resuscitation } \\
\hline $\begin{array}{l}\text { Time to ROSC (min), median } \\
\text { [IQR] }\end{array}$ & $16.0(8.0-29.0)$ & $20.0(11.0-30.0)$ & 0.15 \\
\hline Adrenaline (mg), median [IQR] & $1.0(0.0-2.0)$ & $3.0(0.0-5.0)$ & 0.03 \\
\hline $\begin{array}{l}\text { Initial rhythm VF/VT, n } \\
(\%)\end{array}$ & $12(57.1)$ & $22(31.0)$ & 0.003 \\
\hline APACHE $\square$ score, mean \pm SD & $28.8 \pm 7.1$ & $\begin{array}{l}34.4 \pm \\
5.9\end{array}$ & 0.002 \\
\hline SOFA score, median [IQR] & $9.0(7.5-13.5)$ & $12.0(9.0-15.0)$ & 0.07 \\
\hline
\end{tabular}

Data are presented as mean \pm SD or Interquartile Range (IQR) as appropriate. The p-value represents comparison between groups. Abbreviations: ROSC: return of spontaneous circulation; VF: ventricular fibrillation; VT: ventricular tachycardia; MAP: mean arterial pressure; APACHE $\square$ : acute physiology and chronic health evaluation; SOFA: sequential organ failure assessment.

\section{Figures}




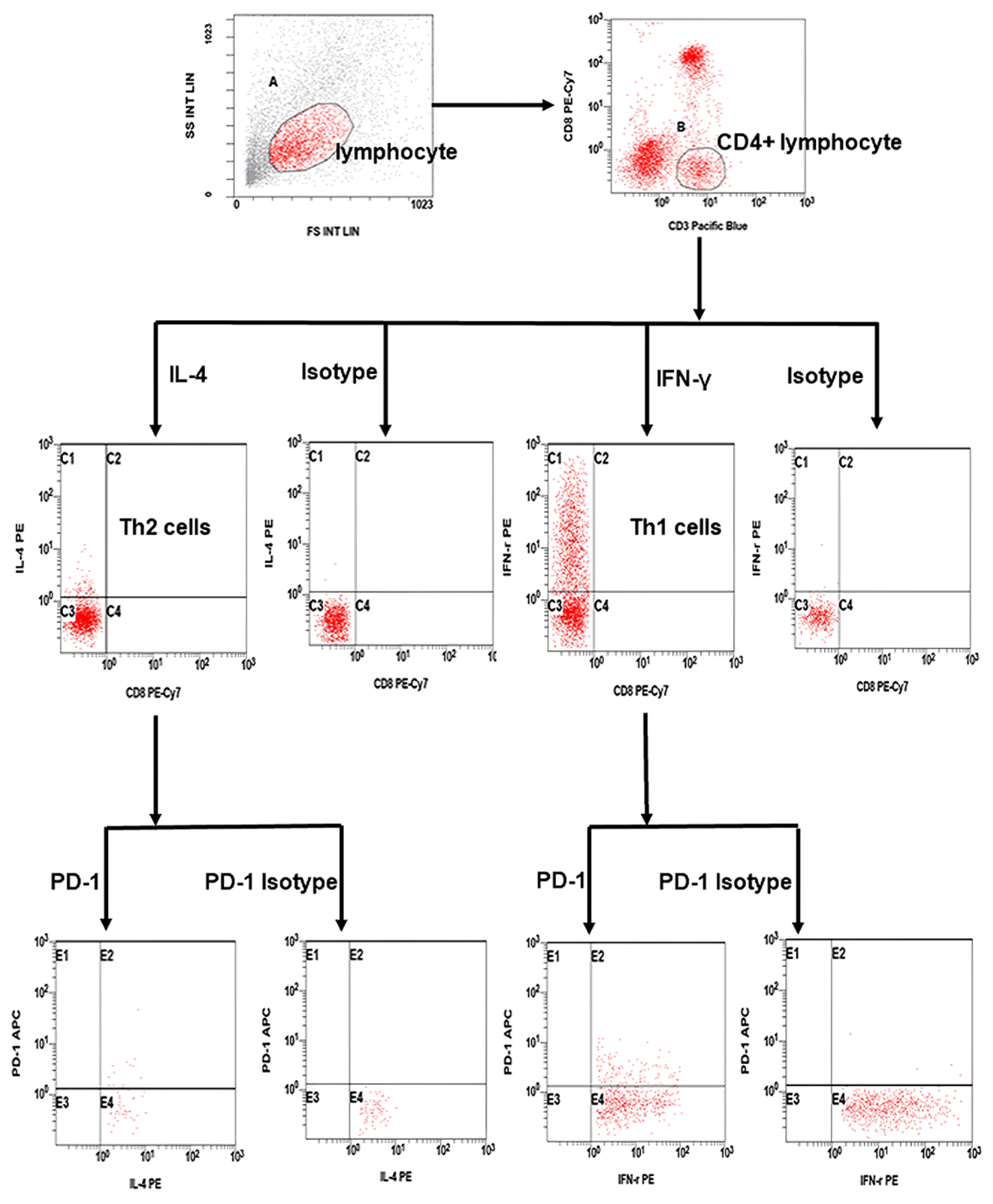

\section{Figure 1}

Representative flow dot plots of PD-1 expression on Th1, Th2, and Th17 cells. Abbreviations: CD: clusterof-differentiation; PD-1: programmed cell death-1; Th: T helper type. 

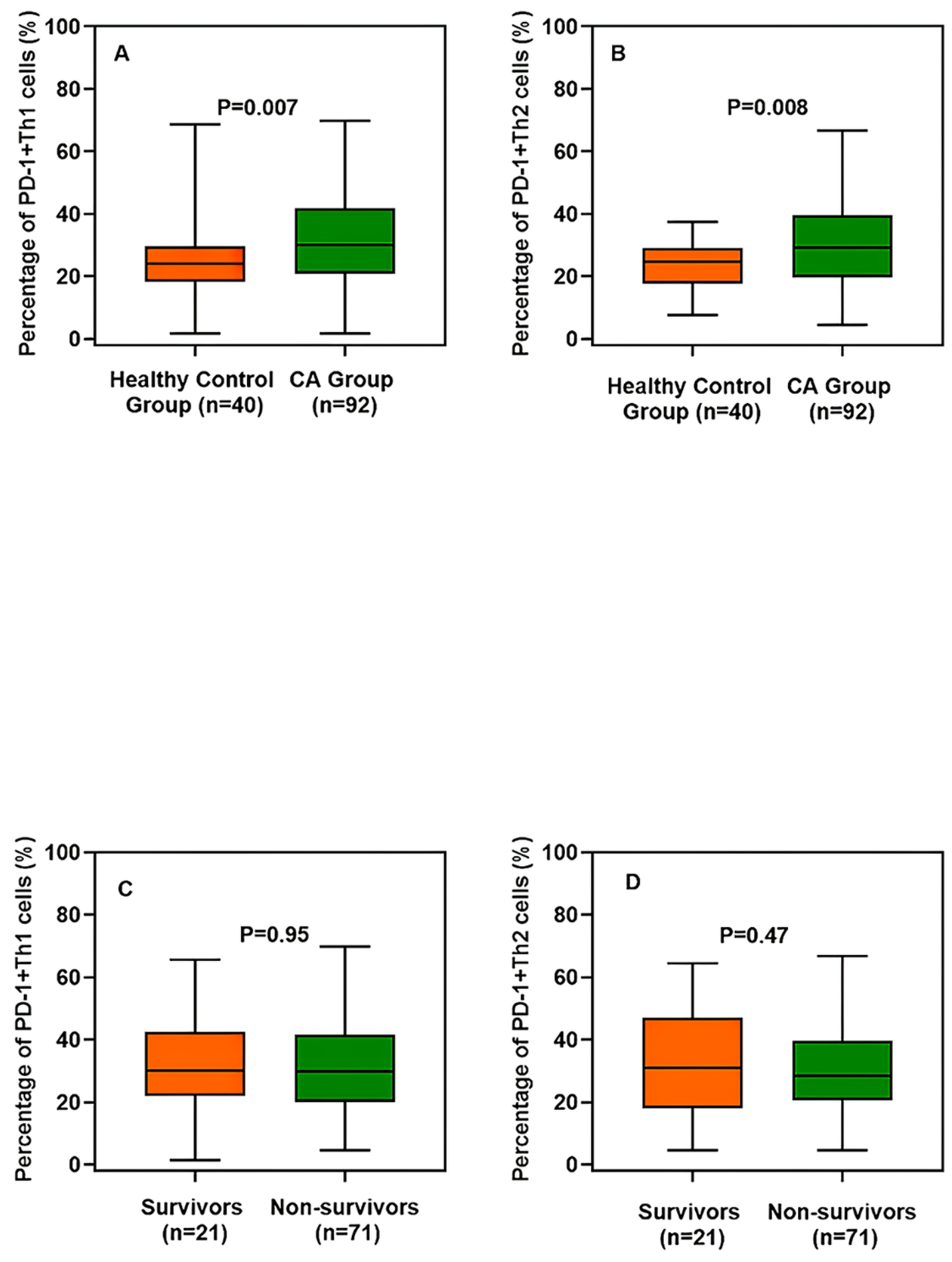

\section{Figure 2}

The expression of PD-1 on circulatory Th1, Th2, and Th17 cells in CA patients after ROSC. There were significant differences compared to the healthy control group $(P<0.05)$. Abbreviations: PD-1: Programmed cell death-1; CA: cardiac arrest; ROSC: return of spontaneous circulation; Th: T helper type. 

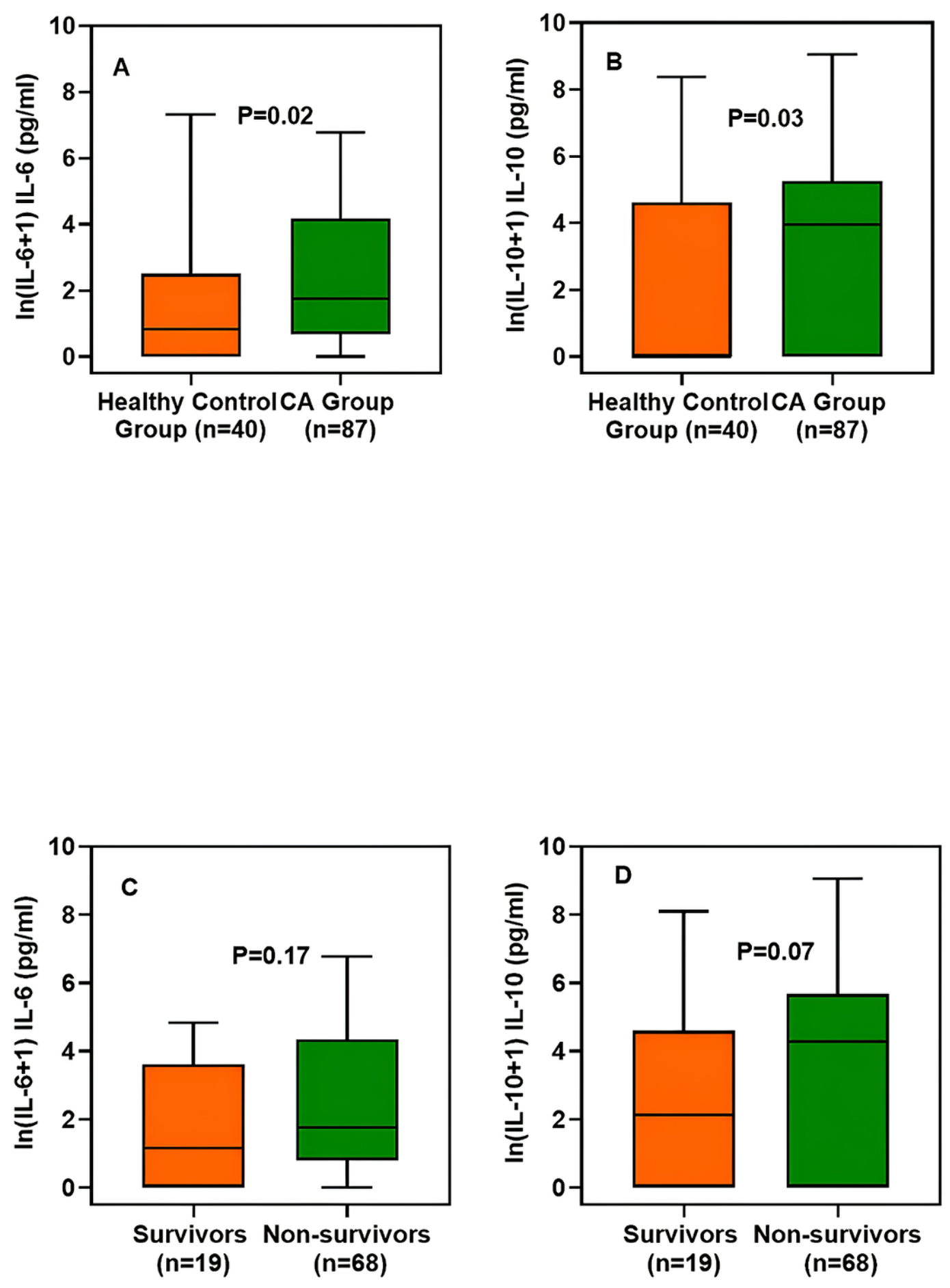

Figure 3

The $(\mathrm{In}+1)$ values of IL- 6 and IL-10 levels in plasma after ROSC in the healthy control group and CA group $(A, B)$. The $(\mathrm{In}+1)$ values of IL-6 and IL-10 levels in plasma in survivors and non-survivors after ROSC (C, D). There were significant differences compared to the healthy control group $(P<0.05)$. Abbreviations: IL: interleukin; CA: cardiac arrest; ROSC: return of spontaneous circulation. 


\section{Supplementary Files}

This is a list of supplementary files associated with this preprint. Click to download.

- Electronicsupplementalmaterial.docx 